\title{
Medical ethics: some reservations
}

\author{
J D Swales School of Medicine, University of Leicester
}

\section{Editor's note}

\begin{abstract}
In this symposium Professor Swales, a professor of medicine, argues that medical ethics cannot be separated conceptually or practically from medical practice and training generally. In direct responses two medical ethicists from America and a British GP rebut this claim. Professor Swales replies briefly to his critics.
\end{abstract}

Those of us who are involved in teaching medical students are painfully familiar with a certain type of letter which we receive with depressing regularity from our colleagues. After the usual expressions of affability and enthusiasm for practical and relevant education we come to the basic complaint. The argument proceeds thus: 'As I am sure you are aware a large proportion ( $10-90$ per cent depending on the circumstances of the case) of patients attending a general practitioner suffer from neurosis / dyspepsia / muscular pain/acute viral infection / the ageing process etc. Nevertheless out of the available 2000 teaching hours only $0 / 3 / 6 /$ Io hours are devoted to psychosomatic medicine / gastroenterology / rheumatology / virology / geriatrics etc. Is it not time that we adopted a more realistic attitude to the needs of the practising doctor?' Clearly, behind the goodwill there is a feeling of injustice in the fight against the forces of conservatism and reaction. Where such genuine enthusiasm exists it is a pity to dampen it but it soon became apparent to me just how disastrous the acceptance of such logic would prove in practice. For one thing of course the relevant conditions belong to overlapping categories. The elderly patient who attends a general practitioner with diffuse muscular pain associated with a viral infection may be upset by her condition. To accept the validity of the case would lead to endless arguments about the division and subdivision of the curricular cake or, to change the metaphor, arguments would centre on what Pickering has described as the droit de seigneur of various specialists over parts of the curriculum (I). There are more fundamental objections: there is no necessary correlation between the frequency of a condition and the available information about it which has to be

Key words

Medical ethics; medical education; ethicists; resource allocation. conveyed to the student. In practice the fragmentation of the curriculum results in the circular-tour principle of teaching, leaving the bewildered student to decide between a multitude of conflicting specialists' views sharing only one common belief that each discipline is central. The note sounded by Mr Ian Kennedy was therefore a familiar one to me. Doctors, although frequently unaware of the fact, are each day making profoundly important ethical judgments. And yet medical ethics occupies only a derisory place (if any) in the curriculum. One might well continue 'Is it not time etc, etc.' My feelings about this can be expressed quite simply. I believe that ethical decisions in medicine cannot be dissociated from clinical decisions: ethical and clinical decisions frequently masquerade as each other and the teaching of the two cannot be carried out independently. In other words 'medical ethics' (and I have some difficulty in defining its boundaries) is too important to have its own separate place in the curriculum. In addition I believe that the development of 'medical ethics' as an identifiable subject worthy of separate teaching ignores the fact that ethical philosophy is qualitatively different from and irrelevant to clinical teaching.

Some of the most important and contentious areas of ethical debate are at the extremes of life. Discussions usually centre upon the need or otherwise to preserve life in the face of irremediable damage. There are however two questions here. The first is the moral question of whether it is justifiable ever to limit efforts to preserve life; the second is a question of medical judgment: when is the damage truly irremediable? Unfortunately for the 'medical ethicist' (if the species ever evolves) these questions cannot be dissociated. As the Arthur case so dramatically showed, problems have a bewildering tendency to shift from the ethical to the clinical domain. This is not a unique feature of that particular and unhappy sequence of events. It is an inevitable fact of clinical life. In that case the question when should life be preserved suddenly became the question, how should life be preserved? The expertise applied to the case became that of the clinician and the pathologist. Let me take another case where an ethical problem has long masqueraded as a clinical one. In the United Kingdom fewer patients over the age of 50 are accepted for chronic dialysis than are accepted in most 
countries of Western Europe. When the reasons for this were examined in a recent study some nephrologists justified their failure to dialyse the elderly on the grounds of clinical unsuitability (2), thereby removing the problem from the ethical arena. Nevertheless eminently satisfactory results have been reported from those centres in which elderly patients have been dialysed. If all patients regarded as suitable elsewhere were taken onto dialysis in the United Kingdom there would be an acute crisis produced by the shortage of dialysis places. The decision not to dialyse elderly patients therefore reflects the relative priority attached to this age group in a competitive struggle for expensive lifesaving techniques. To take an analogous case with slightly different undercurrents; a decision to place a brain-damaged neonate on a ventilator could be seen as one which strictly belongs to the field of ethical judgments about the value of life. But what if the demand for ventilators and their support staff exceeds their supply? What if we have to deny the facility to the neonate with a potentially reversible illness? It is no answer to say that we campaign for adequate facilities if that campaign simply shifts resources away from say the care of the aged or life-preserving facilities elsewhere, as inevitably it must do since all resources are finite. It is self-evident that the value judgments which a clinician makes are part and parcel of his work. Ethical judgments cannot be disentangled from clinical judgments. Medical ethics cannot be segregated as a discrete subject without losing all relevance and meaning.

It might well be argued at this point that there is therefore a strong argument for introducing the 'ethicist' into clinical work in order to improve the quality and expertise of the judgments which the clinician has to make. After all it is common practice to ask, say, the immunologist or the haematologist when their knowledge and skills seem relevant. Alternatively, why not extend the work of the local ethical committees which are at the moment primarily concerned with research projects? Such rather naive suggestions completely misunderstand the nature of ethics and ethical philosophy. Clinical judgments may have an element of uncertainty in them but fundamentally they are based upon the application of inductive scientific method, ie hypotheses are regularly tested and corroborated or rejected by direct observation. Ethical statements are essentially metaphysical, ie although justifiably subject to discussion and debate no final proof or disproof exists. A specific example may reveal this more clearly. The contentious debate about the termination of pregnancy centres upon the point at which an individual's life can be said to begin. This in turn, turns upon the definition of individual life. This is not an inductive observation: it is a matter of assertion and belief. It would not be resolved by an expert opinion unless one happened to share that expert's belief in which case his opinion would be superfluous.

It might well be argued at this point that what I have said goes against common experience: that there are, with a few exceptions, generally accepted standards which doctors take as a guide to their conduct. There is, for instance, the principle that the welfare of the patient is paramount. This is derived from a simple fact. Doctors' ethical judgments in most cases are derived from a utilitarian approach. Doctors are in other words pragmatists. Their judgment of what is best is determined by outcome in terms of good or harm. Clinicians would not dissent from Bertrand Russell's summary of the ethics of science 'it is better to do a little good than much harm' (3). In medicine this utilitarianism may be described in religious language with the use of such terms as the sanctity of life. On the other hand in practice battles over such issues as abortion or euthanasia are almost always fought on utilitarian and not religious grounds. The appeal of each side is to the outcome; the effect upon the patient, the patient's relatives, staff and society as a whole. This is not a surprising state of affairs as our society is not a theocratic one and includes influential people of all religions and none. An appeal to a particular religious belief is unlikely to gain much support whilst the claim that one's proposed action results in more good and less harm than one's opponents at least ensures that one is using a language which will be acceptable to the largest number of people, even if the concepts of good and harm are somewhat ambiguous. If I am correct in my analysis the position of the ethical expert becomes untenable. It is difficult to see an adherent of a particular religious belief fulfilling the role. Although he or she may in some cases have the advantage of a well defined outlook and guiding principles these will be shared by only a minority of the patients and doctors involved in the ethically difficult situation. The alternative is to have a different sort of expert, someone perhaps characterised by wisdom and learning, who could advise on the preferred action as a result of careful dissection of the consequences of a particular course. This individual would therefore assess how much good and how much harm we were doing. However, the difficulty here is that this can only be done with the knowledge and experience of those who are working in that particular field (including both medical and non-medical workers). The problem also demands discussion with those most immediately involved, ie the patients and their relatives. The expertise required is an expertise in the disputed clinical area, not in the non-science of medical ethics. I would accept that the experienced and conscientious expert in a particular field has a great deal to contribute to resolving the ethical dilemmas of the noviciate but this expertise is technical and not ethical. Indeed ethical expertise is a meaningless concept.

I would certainly support the view that discussion and debate of such dilemmas is a useful activity. What I cannot accept is that there is an external expert authority best able to judge the correctness or otherwise of other actions, or that there is a discipline of medical ethics which can somehow throw light on what we should do. There is a good precedent for my reservations. A centuries-old debate over the nature of 
inductive scientific method has given rise to an extensive literature on the philosophy of science which attempts to analyse what scientists do. This is a fascinating academic discipline but one consequence which is conspicuously absent is any effect upon scientific research. The vast majority of those active in scientific research have remained wholly ignorant of the philosophical basis of what they are doing. As was noted by Karl Marx in the last century philosophers have been content to describe the world and not to change it. This is equally true of ethical philosophy. In our desire to advance medicine by the development of relevant and appropriate specialties we should exercise scientific caution and recognise the true nature of ethical judgments.

\section{References}

(I) Pickering GW. The quest for excellence in medical education: a personal survey. Nuffield Provincial Hospitals Trust. Oxford University Press, 1978: 42.

(2) Parsons V, Lock P. Triage and the patient with renal failure. Fournal of medical ethics 1980; 6: 173-176.

(3) Russell B. The scientific outlook. London: Allen and Unwin, 1954. 